\title{
Assessing sources of uncertainty in formaldehyde air mass factors over tropical South America: Implications for top-down isoprene emission estimates
}

\section{Citation}

Barkley, Michael P., Thomas P. Kurosu, Kelly Chance, Isabelle De Smedt, Michel Van Roozendael, Almut Arneth, Daniel Hagberg, and Alex Guenther. 2012. "Assessing Sources of Uncertainty in Formaldehyde Air Mass Factors over Tropical South America: Implications for Top-down Isoprene Emission Estimates." Journal of Geophysical Research: Atmospheres 117 (D13): n/a-n/ a. https://doi.org/10.1029/2011jd016827.

\section{Permanent link}

http://nrs.harvard.edu/urn-3:HUL.InstRepos:41461232

\section{Terms of Use}

This article was downloaded from Harvard University's DASH repository, and is made available under the terms and conditions applicable to Other Posted Material, as set forth at http:// nrs.harvard.edu/urn-3:HUL.InstRepos:dash.current.terms-of-use\#LAA

\section{Share Your Story}

The Harvard community has made this article openly available.

Please share how this access benefits you. Submit a story.

Accessibility 


\title{
Assessing sources of uncertainty in formaldehyde air mass factors over tropical South America: Implications for top-down isoprene emission estimates
}

\author{
Michael P. Barkley, ${ }^{1}$ Thomas P. Kurosu, ${ }^{2,3}$ Kelly Chance, ${ }^{2}$ Isabelle De Smedt, ${ }^{4}$ \\ Michel Van Roozendael, ${ }^{4}$ Almut Arneth, ${ }^{5,6}$ Daniel Hagberg, ${ }^{5}$ and Alex Guenther ${ }^{7}$ \\ Received 2 September 2011; revised 18 May 2012; accepted 23 May 2012; published 6 July 2012.
}

[1] We use a nested-grid version of the GEOS-Chem chemistry transport model, constrained by isoprene emissions from the Model of Emissions of Gases and Aerosols from Nature (MEGAN), and the Lund-Potsdam-Jena General Ecosystem Simulator (LPJ-GUESS) bottom-up inventories, to evaluate the impact that surface isoprene emissions have on formaldehyde (HCHO) air-mass factors (AMFs) and vertical column densities (VCDs) over tropical South America during 2006, as observed by the Scanning Imaging Absorption Spectrometer for Atmospheric Chartography (SCIAMACHY) and Ozone Monitoring Instrument (OMI). Although the large-scale seasonal variability of monthly mean HCHO VCDs is typically unaffected by the choice of bottom-up inventory, large relative differences of up to $\pm 45 \%$ in the HCHO VCD can occur for individual regions and months, but typically most VCD differences are of order $\pm 20 \%$. These relative changes are comparable to those produced by other sources of uncertainty in the AMF including aerosols and surface albedo, but less than those from clouds. In a sensitivity test, we find that top-down annual isoprene emissions inferred from SCIAMACHY and OMI $\mathrm{HCHO}$ vertical columns can vary by as much as $\pm 30-50 \%$ for each instrument respectively, depending on the region studied and the a priori isoprene emissions used. Our analysis suggests that the influence of the a priori isoprene emissions on HCHO AMFs and VCDs is therefore non-negligible and must be carefully considered when inferring top-down isoprene emissions estimates over this, or potentially any other, region.

Citation: Barkley, M. P., T. P. Kurosu, K. Chance, I. De Smedt, M. Van Roozendael, A. Arneth, D. Hagberg, and A. Guenther (2012), Assessing sources of uncertainty in formaldehyde air mass factors over tropical South America: Implications for top-down isoprene emission estimates, J. Geophys. Res., 117, D13304, doi:10.1029/2011JD016827.

\section{Introduction}

[2] Formaldehyde (HCHO) is a key atmospheric constituent produced from the oxidation of volatile organic compounds (VOCs). While the oxidation of methane sustains low (subppbv) background levels, over continental regions, the

\footnotetext{
${ }^{1}$ EOS Group, Department of Physics and Astronomy, University of Leicester, Leicester, UK.

${ }^{2}$ Harvard-Smithsonian Center for Astrophysics, Cambridge, Massachusetts, USA.

${ }^{3}$ Now at Jet Propulsion Laboratory, Pasadena, California, USA.

${ }^{4}$ Belgian Institute for Space Aeronomy (BIRA-IASB), Brussels, Belgium.

${ }^{5}$ Department of Physical Geography and Ecosystems Analysis, Geobiosphere Science Center, Lund University, Lund, Sweden.

${ }^{6}$ Atmospheric Environmental Research and Institute of Meteorology and Climate Research, Karlsruhe Institute of Technology, Karlsruhe, Germany.

${ }^{7}$ National Center of Atmospheric Research, Boulder, Colorado, USA

Corresponding author: M. P. Barkley, EOS Group, Department of Physics and Astronomy, University of Leicester, University Road, Leicester LE1 7RH, UK. (mpb14@le.ac.uk)

(C2012. American Geophysical Union. All Rights Reserved. 0148-0227/12/2011JD016827
}

oxidation of short-lived VOCs from anthropogenic, biogenic and pyrogenic sources, along with direct emissions from fires and industrial processes, can produce large ( $>5 \mathrm{ppbv})$ amounts of $\mathrm{HCHO}$ within the boundary layer. Since $\mathrm{HCHO}$ has a short atmospheric lifetime (approximately several hours) owing to photolysis and reaction with the hydroxyl radical $(\mathrm{OH})$, it is a useful tracer for inferring surface emissions [Palmer et al., 2003]. Model studies indicate that isoprene, the dominant biogenic VOC emitted from plants [Guenther et al., 2006], is rapidly oxidized to form $\mathrm{HCHO}$ with a high yield and largely controls HCHO column variability over densely vegetated areas [Stavrakou et al., 2009a]. Yet although the importance of isoprene within climate is well established, its emissions are poorly quantified [Arneth et al., 2008]. Consequently, satellite measurements of $\mathrm{HCHO}$ columns have been used in several studies to provide top-down constraints on isoprene emissions [see, e.g., Stavrakou et al., 2009b]. Satellite-based estimates are particularly valuable over tropical ecosystems, where isoprene emissions are greatest and bottom-up inventories least well constrained [Barkley et al., 2008, 2009]. However, the errors associated with satellite derived emissions are large owing to significant uncertainties in the $\mathrm{HCHO}$ column 
retrieval itself, and also the selected chemistry-transport model (CTM) used to infer the estimates (e.g., owing to simplified parameterizations of isoprene oxidation chemistry).

[3] The HCHO vertical column retrieval consists of twosteps. First, HCHO slant column densities (SCDs) along the instruments line-of-sight are obtained through the spectral fitting of trace gas absorption cross-sections to measured solar UV backscatter spectra. Second, the slant columns are converted to vertical column densities (VCDs) after division by an air-mass factor $(\mathrm{AMF}=\mathrm{SCD} / \mathrm{VCD})$ which accounts for the satellite viewing geometry, $\mathrm{HCHO}$ vertical distribution, surface reflectance, and atmospheric scattering by air-molecules, aerosols, and clouds [Palmer et al., 2001]. Since the AMF computation can significantly affect the accuracy of the final $\mathrm{HCHO}$ product, it is this aspect of the retrieval we focus on. In particular, we draw attention to the influence on the AMF of the $\mathrm{HCHO}$ vertical distribution, which is typically provided by a CTM driven by a specified bottom-up isoprene emission inventory - in most cases an application of the canopy-scale Model of Emissions of Gases and Aerosols from Nature (MEGAN), developed by Guenther et al. [2006]. Although the estimated AMF error due to uncertainties in the HCHO vertical profile is estimated to be only about $10-20 \%$ [Millet et al., 2006; Palmer et al., 2006; De Smedt et al., 2008], to our knowledge no-one has yet assessed this error component using model HCHO profiles based on more than one isoprene emission inventory. In this work, we attempt to address this oversight by assessing HCHO AMFs and VCDs over tropical South America, utilizing a recently developed GEOS-Chem CTM nested grid simulation of Amazonian biogenic emissions and tropospheric chemistry [Barkley et al., 2011]. The nested grid is unique in that it can be forced with isoprene emissions from MEGAN, or alternatively, from a leaf-scale algorithm which is coupled to the LPJ-GUESS dynamic vegetation model [Arneth et al., 2007]. Here we run GEOS-Chem with both inventories using the subsequent $\mathrm{HCHO}$ profiles to compute AMFs to apply to slant columns retrieved by the SCIAMACHY [Bovensmann et al., 1999] and OMI instruments [Levelt et al., 2006], in order to examine the relative changes in the resulting HCHO VCD distributions. Our goal is to determine the importance of the a priori isoprene emissions on the final HCHO VCDs, as compared with influence of other AMF inputs (e.g., aerosols). We stress that this work is not a full-error analysis of absolute column magnitudes, nor an inter-comparison of the two satellite products.

[4] In section 2 we provide a brief overview of the GEOSChem model, and describe the SCIAMACHY and OMI HCHO slant column retrievals and the computation of their AMFs. In section 3 we present the results of our sensitivity analysis, and then in section 4 we examine the impact of the different a priori isoprene inventories on subsequent top-down isoprene emission estimates. We conclude the paper in section 5 .

\section{Data and Methods}

\subsection{GEOS-Chem Chemistry Transport Model}

[5] Since Barkley et al. [2011] describe the GEOS-Chem Amazon simulation in great detail, for brevity, here we only give a short description. The nest-grid has a horizontal resolution of $0.667^{\circ} \times 0.5^{\circ}$ (longitude $\times$ latitude), and 47 vertical levels extending from the surface to $0.01 \mathrm{hPa}$. The model is driven using GEOS-5 meteorology [Rienecker et al., 2008], which is updated every 3-6 hours. Tracer mixing ratios from an off-line global $4^{\circ} \times 5^{\circ}$ simulation provide 3 -hourly boundary conditions to the grid-edges. Based on a previous model evaluation [Barkley et al., 2011], we use an updated chemical mechanism [Paulot et al., 2009a, 2009b] to simulate $\mathrm{O}_{3}-\mathrm{NO}_{\mathrm{x}}$-VOC-aerosol photochemistry. To quantify the effect of the input isoprene emissions on the HCHO AMFs and VCDs, we run GEOS-Chem with four emission scenarios for the year 2006 using two different variants of the MEGAN and LPJ-GUESS inventories taken from the study of Barkley et al. [2011], as summarized in Table 1 and shown in Figure S1 of the auxiliary material. ${ }^{1}$ Substantial differences exist between the isoprene emissions predicted by these models owing to their different assignment of basal emission capacities, choice of driving algorithms and forcing meteorology, and their different vegetation distributions and leaf-area [Guenther et al., 2006; Arneth et al., 2007]. For example, MEGAN uses MODIS leaf-area applied to static vegetation maps where as LPJ-GUESS explicitly simulates vegetation foliage [Barkley et al., 2011]. MEGAN isoprene emissions tend to be highest along the Brazilian border with Peru and Bolivia owing to the presence of bamboo forest, where as LPJ-GUESS emissions are typically higher in the southeast owing to emissions from broad leaf rain green trees [Barkley et al., 2011]. Owing to a lack of observational with which to validate the simulated emissions during our study period and given the large uncertainties of tropical isoprene emissions, we have to assume each model is viable despite notable differences in their annual totals (Table 1). The choice of inventory can have a large impact on the simulated $\mathrm{HCHO}$ profiles; in extreme cases differences of up to 4 ppbv can exist within the lowest $3 \mathrm{~km}$ of the atmosphere (see, e.g., Figure S2).

\subsection{SCIAMACHY and OMI HCHO Slant Columns}

[6] SCIAMACHY is a passive UV-Vis-NIR grating spectrometer situated on board ESA's ENVISAT satellite [Bovensmann et al., 1999]. For the majority of its polar sunsynchronous orbit, SCIAMACHY makes measurements in an alternating limb and nadir sequence, crossing the equator at 10:00 local time (LT). In nadir mode, the ground swath has fixed dimensions of $960 \times 30 \mathrm{~km}^{2}$ (across $\times$ along track) with a nominal pixel size of $60 \times 30 \mathrm{~km}^{2}$. Global coverage is achieved at the equator within about 6 days. HCHO slant columns are retrieved from nadir UV-spectra using differential optical absorption spectroscopy, as described in De Smedt et al. [2008]. A spectral fitting window of 328.5-346 nm is used to reduce fitting uncertainties due to a polarization anomaly at $350 \mathrm{~nm}$, and a strong $\mathrm{O}_{4}$ absorption band centered near $360 \mathrm{~nm}$. Besides the fitting of the absorption cross sections of $\mathrm{HCHO}$ and other interfering gases, corrections for the Ring effect and a linear intensity offset are applied, along with a fifth order polynomial closure term. A reference sector adjustment is also made based on daily observations over the central Pacific Ocean $\left(140-160^{\circ} \mathrm{W}\right)$ [De Smedt et al., 2008; De Smedt, 2011]. Mean (systematic) fitting uncertainties of a $\mathrm{HCHO}$ slant column measurement usually range between $30-150 \%$.

${ }^{1}$ Auxiliary materials are available in the HTML. doi:10.1029/ 2011JD016827. 
Table 1. Description of the Air Mass Factor Sensitivity Simulations for the Year 2006

\begin{tabular}{|c|c|c|}
\hline Scenario & Isoprene Emissions ( $\operatorname{Tg} \mathrm{C}$ ) & Description \\
\hline SCIA* or OMI* & 154 & $\begin{array}{l}\text { Default scenario for each instrument. Isoprene emissions calculated using a } \\
\text { 5-layer canopy model and a combination of Guenther et al. [1999, 2006] } \\
\text { algorithms }\end{array}$ \\
\hline MEGAN $^{\prime}$ & 98 & $\begin{array}{l}\text { As above, but with isoprene emissions scaled by } 0.635 \text { to match the monthly } \\
\text { mean emissions from the study of Müller et al. }[2008]^{\mathrm{b}}\end{array}$ \\
\hline LPJ(GC) & 75 & $\begin{array}{l}\text { Emissions based on the LPJ-GUESS model forced with GEOS-Chem's } \\
\text { GEOS-5 meteorology }\end{array}$ \\
\hline LPJ(CRU) & 90 & $\begin{array}{l}\text { Emissions based on the LPJ-GUESS model forced with its default CRU } \\
\text { meteorology }\end{array}$ \\
\hline BL & 154 & $\begin{array}{l}\text { As the default scenario but with a non-local boundary layer mixing scheme } \\
\text { employed in GEOS-Chem }^{\mathrm{d}}\end{array}$ \\
\hline ALB & 154 & $\begin{array}{l}\text { As the default scenario but using the Kleipool et al. [2008] surface } \\
\text { reflectances in the AMF computation }\end{array}$ \\
\hline AOD & 154 & $\begin{array}{l}\text { As the default scenario but without an aerosol correction applied } \\
\text { (i.e. AOD }=0 \text { ) in the AMF computation }\end{array}$ \\
\hline $\mathrm{CF}$ & 154 & $\begin{array}{l}\text { As the default scenario, but assuming a }+0.1 \text { cloud fraction error in the } \\
\text { AMF computation }\end{array}$ \\
\hline СТP & 154 & $\begin{array}{l}\text { As the default scenario, but assuming a }-60 \mathrm{hPa} \text { error in cloud top pressure } \\
\text { in the AMF computation }\end{array}$ \\
\hline
\end{tabular}

${ }^{a}$ This (hybrid) emission scheme, which uses MEGAN v2.1 basal emission factors, is fully described in Barkley et al. [2011].

${ }^{\mathrm{b}}$ The 0.635 scaling factor is based on both 2005 and 2006 emissions [see Barkley et al., 2011].

${ }^{\mathrm{c}}$ Data from the Climate Research Unit of the University of East Anglia (http://www.cru.uea.ac.uk/).

'The non-local scheme includes 'local' mixing between adjacent model layers and, depending on the stability of the PBL, 'non-local' mixing due to turbulent eddies [Lin and McElroy, 2010].

${ }^{\mathrm{e}}$ Estimated uncertainties based on the study of Acarreta et al. [2004]; here we use a +0.1 error in cloud fraction to determine the likely maximum range of this effect on the AMFs and VCDs.

[7] The Dutch-Finnish Ozone Monitoring Instrument (OMI) [Levelt et al., 2006], is a nadir-viewing near-UV/ visible charged-couple device (CCD) spectrometer situated on board NASA's Aura satellite. OMI also orbits the Earth in a sun-synchronous polar orbit, but with an equator crossing time of 13:30 LT. OMI has a $114^{\circ}$ field-of-view producing a $2600 \mathrm{~km}$ wide swath containing 60 cross-track pixels that range in size from $14 \times 26 \mathrm{~km}^{2}$ at nadir, to $28 \times$ $160 \mathrm{~km}^{2}$ at the swath edges. HCHO slant columns are retrieved for each of the 60 cross track pixels, through a direct non-linear least squares fitting of spectral radiances within the interval $327.5-356.5 \mathrm{~nm}$, as described in Chance [2002] and Kurosu et al. [2004]. The cross-sections of $\mathrm{HCHO}$ and other absorbers are fitted, along with a Ring effect correction, closure polynomials and optional spectral shift and squeeze parameters. The retrieval algorithm also includes dynamic calibration of solar and radiance wavelengths, an under-sampling correction, computation of common model residual spectrum, and a de-striping algorithm to minimize cross-track striping. Fitting uncertainties of a single $\mathrm{HCHO}$ slant column measurement typically range between $40-100 \%$ [Chance, 2002].

\subsection{Calculation of SCIAMACHY and OMI AMFs}

[8] To establish consistent AMFs for each instrument we construct look-up tables using monthly averaged $\mathrm{HCHO}$ profiles and aerosol optical depths from GEOS-Chem, appropriate to each instrument's overpass time (see Figures S3 and S4). These serve as input to the radiative transfer model LIDORT [Spurr et al., 2001], which calculates scattering weights that represent the sensitivity of the backscattered radiance to the $\mathrm{HCHO}$ abundance at each altitude, but which also effectively decouples this dependency from the profile shape [Palmer et al., 2001]. We parameterize each look-up table as a function of location (i.e. surface pressure), solar zenith angle, cloudtop pressure, and scan angle. We account for partially cloudy scenes using the approach of Martin et al. [2002], which assumes the total AMF is the brightness-weighted average of the air mass factors for the clear $\left(A M F_{c l r}\right)$ and cloudy $\left(A M F_{c l d}\right)$ pixel sub-scenes:

$$
\mathrm{AMF}=\frac{A M F_{c l r} \cdot R_{c l r} \cdot(1-f)+A M F_{c l d} \cdot R_{c l d} \cdot f}{R_{c l r} \cdot(1-f)+R_{c l d} \cdot f}
$$

where $f$ is the cloud fractional coverage, and $R_{c l d}$ and $R_{c l r}$ are the sub-scene reflectivities calculated by LIDORT, given by:

$$
\begin{aligned}
& R_{c l r}=\frac{\pi I_{c l r}}{I_{0} \cos \theta_{S Z A}}, \\
& R_{\text {cld }}=\frac{\pi I_{\text {cld }}}{I_{0} \cos \theta_{S Z A}},
\end{aligned}
$$

with $I_{0}$ the solar irradiance at the top of the atmosphere perpendicular to the solar beam, $\theta_{S Z A}$ the solar zenith angle, and $I_{c l r}$ and $I_{c l r}$ the clear and cloudy backscattered radiances. $R_{c l r}$ depends on wavelength, surface pressure, surface albedo and solar/viewing geometry; $R_{\text {cld }}$ also depends on cloudtop pressure and cloud albedo [Martin et al., 2002]. The AMFs are computed at $340 \mathrm{~nm}$ for SCIAMACHY and $328 \mathrm{~nm}$ for OMI; the different sensitivities of the two instruments for example scenes are shown in the auxiliary material Figure S5). A shorter wavelength is used for OMI to better represent the air mass of its wider fitting window; our tests indicate AMF differences due to the two 


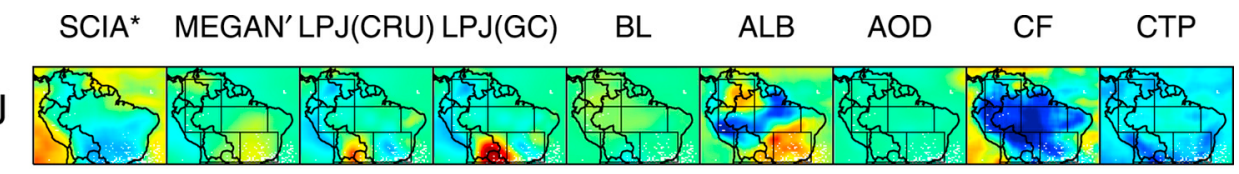

$\mathrm{F}$

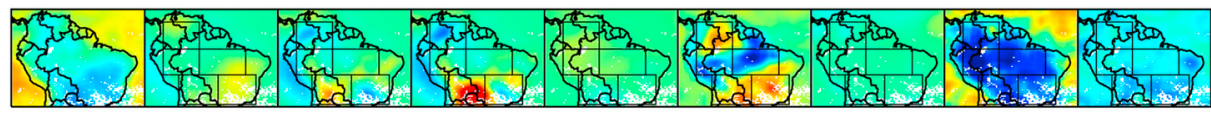

M

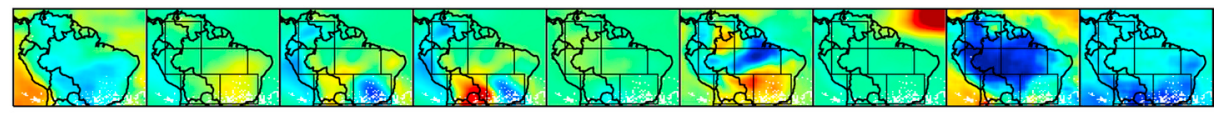

A

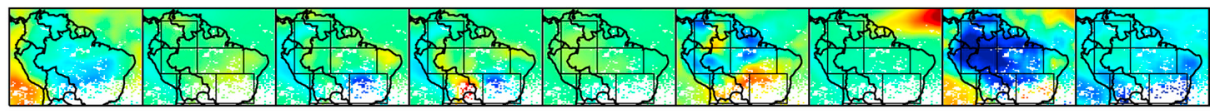

$M$

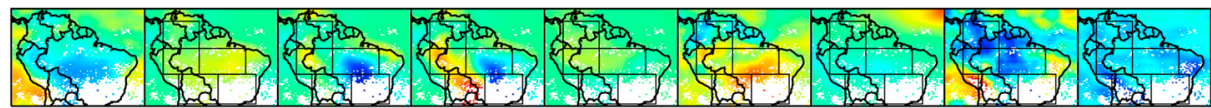

$\mathrm{J}$

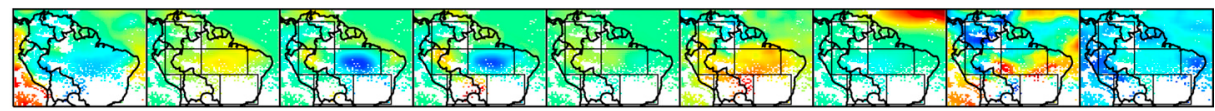

J

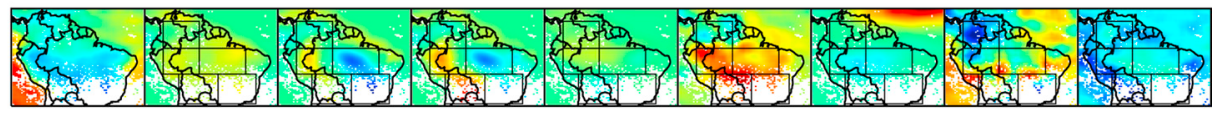

A

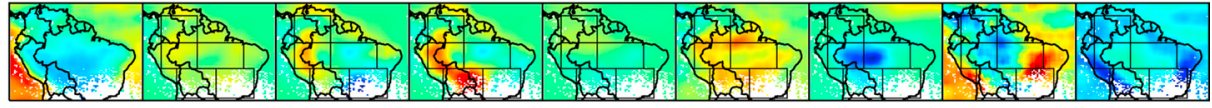

S

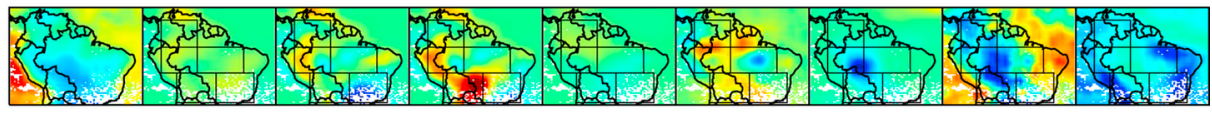

$\mathrm{O}$

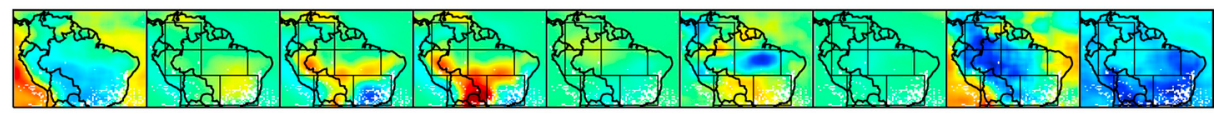

$\mathrm{N}$

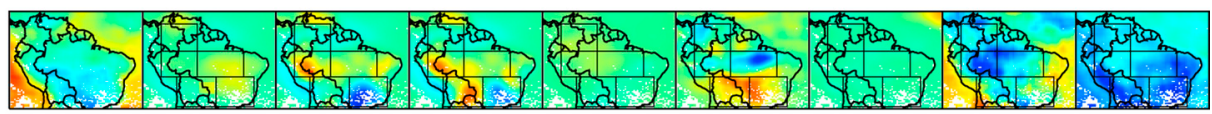

D
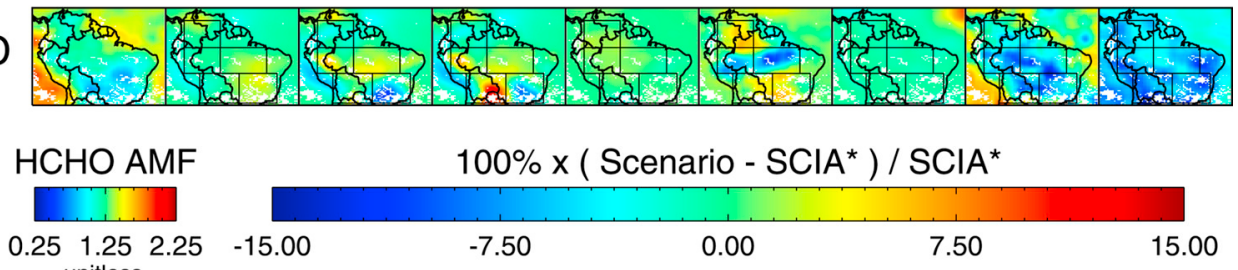

$100 \% \times\left(\right.$ Scenario $\left.-\mathrm{SCIA}^{*}\right) / \mathrm{SCI}{ }^{*}$

unitless

$-7.50$

0.00

7.50

15.00

Figure 1. Monthly mean air mass factors (AMFs) for 2006, corresponding to 09:00-11:00 local time, for SCIAMACHY (first column) using a HCHO climatology based on the MEGAN bottom-up emission inventory. The remaining columns show the relative changes in the SCIAMACHY AMFs arising from the sensitivity simulations outlined in Table 1. The SCIAMACHY AMF data have been averaged onto the nested $0.667^{\circ} \times 0.5^{\circ}$ grid using observations with cloud cover $\leq 40 \%$ and smoothed with a $9 \times 9$ box-filter to remove noise. White-colored regions correspond to areas with no usable SCIAMACHY data. The overlain boxes (in black) correspond to the regional areas (north, west, east, southwest, and southeast) used in subsequent analyses (see section 3).

wavelengths alone are about $5 \%$. Clouds are characterized as Lambertian reflectors with an albedo of 0.8 [Chance, 2002], with the cloud fraction and cloud-top pressure for each observation provided by the respective SCIAMACHY
FRESCO v5 [Koelemeijer et al., 2002], and OMI $\mathrm{O}_{2}-\mathrm{O}_{2}$ [Acarreta et al., 2004] cloud algorithms. Scenes with $>40 \%$ cloud cover are removed from our analysis. For clear-sky conditions, the surface albedo (at $\sim 360 \mathrm{~nm}$ ) is taken from 


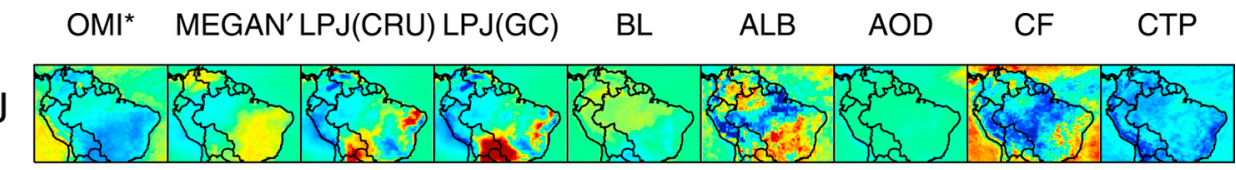

$\mathrm{F}$

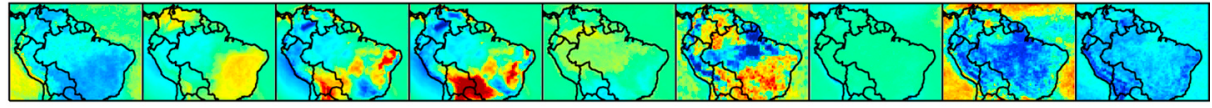

M

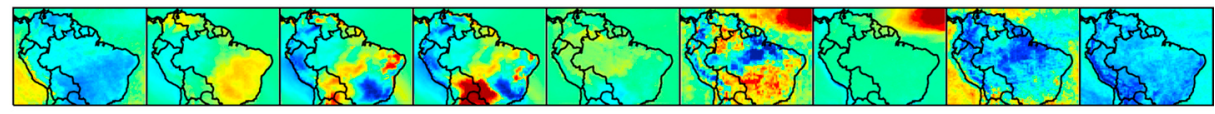

A

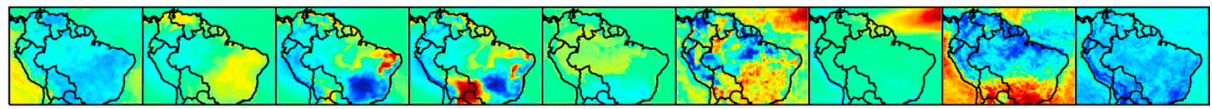

M

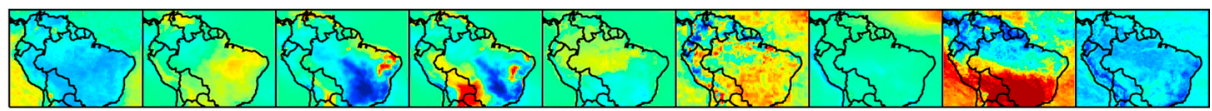

$J$

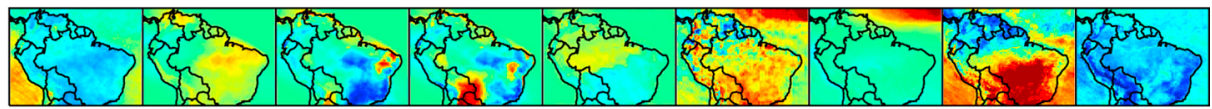

J

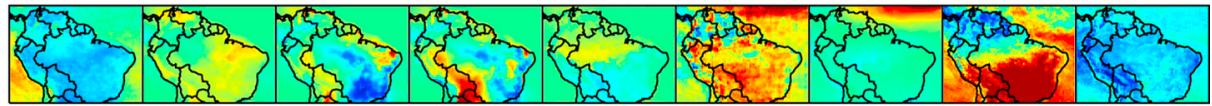

A

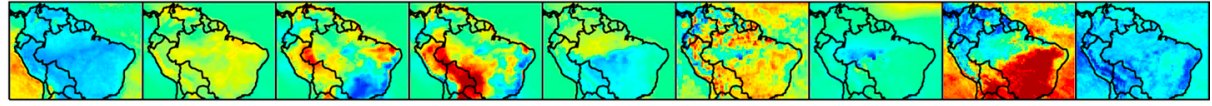

$\mathrm{S}$

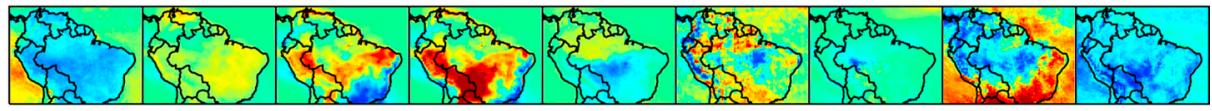

$\mathrm{O}$

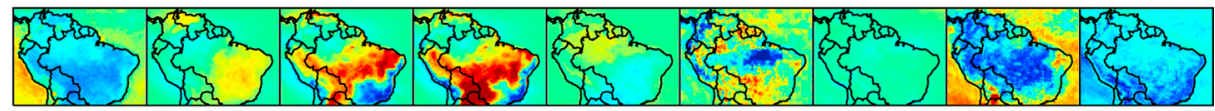

$\mathrm{N}$

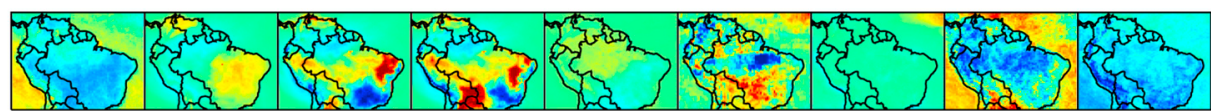

D
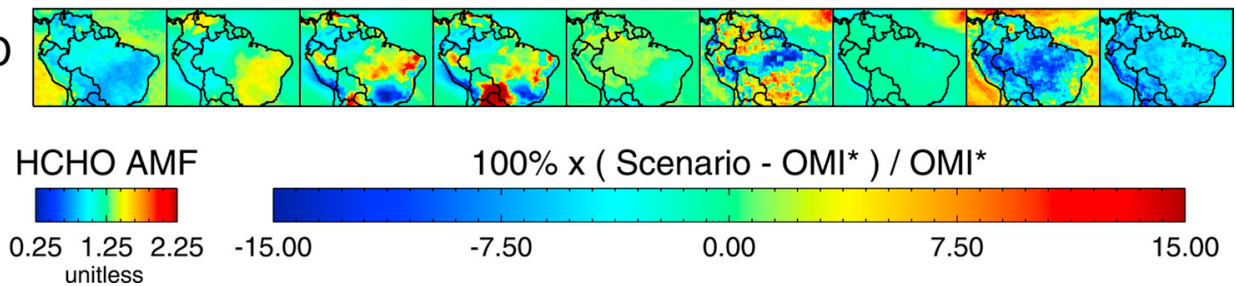

$100 \% \times\left(\right.$ Scenario $\left.-\mathrm{OMI}^{*}\right) / \mathrm{OMI}^{*}$

unitless

Figure 2. Monthly mean air mass factors (AMFs) for 2006, corresponding to 12:00-15:00 local time, for OMI (first column) using a HCHO climatology based on the MEGAN bottom-up emission inventory. The remaining columns show the relative changes in the OMI AMFs arising from the sensitivity simulations outlined in Table 1. The OMI AMF data have been averaged onto the nested $0.667^{\circ} \times 0.5^{\circ}$ grid using observations with cloud cover $\leq 40 \%$.

a climatological database derived from TOMS surface reflectance measurements [Herman and Celarier, 1997].

\section{Results}

\subsection{Sensitivity to Surface Isoprene Emissions}

[9] We define two scenarios: SCIA* and OMI* which use isoprene emissions based on MEGAN (see Table 1), as a baseline with which to compare the impact of the other bottom-up emissions on the AMFs and VCDs. AMFs based on this scenario range from $0.5-1.9$ over land, and $0.7-2.2$ over the oceans (see Figures 1 and 2). AMFs are lower over land owing to $\mathrm{HCHO}$ profile shapes that peak nearer the surface where scattering weights are smallest, in contrast to oceanic HCHO profiles that are more uniform with altitude (Figure S5) [see also Palmer et al., 2001]. The corresponding monthly mean HCHO VCD distributions, shown in the first column of Figures 3 and 4, respectively, have a clear 


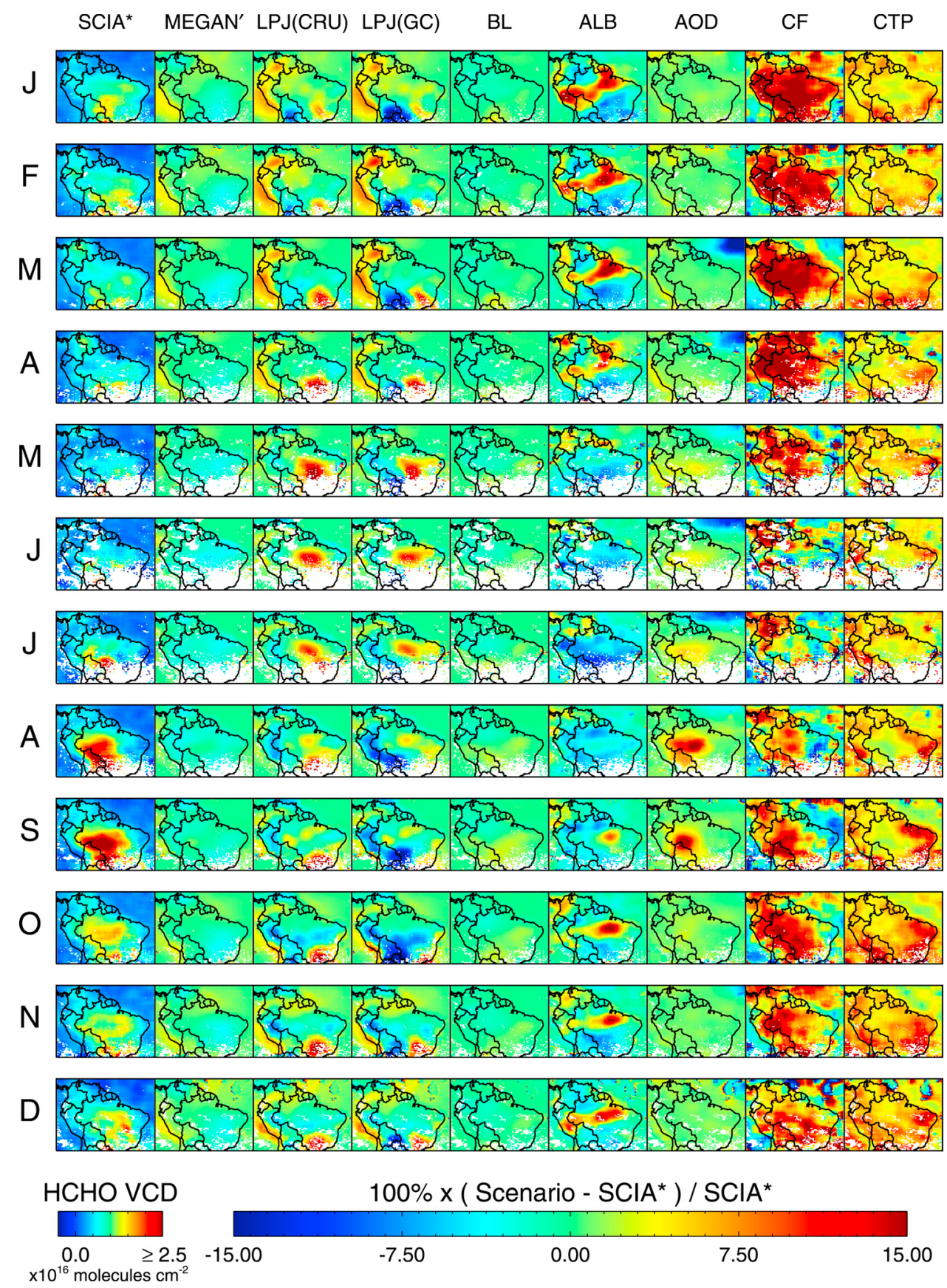

Figure 3. Monthly mean HCHO vertical columns for 2006 corresponding to 09:00-11:00 local time, as observed by SCIAMACHY (first column) using AMFs based on the MEGAN bottom-up emission inventory. The remaining columns show the relative changes in the SCIAMACHY HCHO VCDs arising from the sensitivity simulations outlined in Table 1. The SCIAMACHY data have been averaged onto the nested $0.667^{\circ} \times 0.5^{\circ}$ grid using observations with cloud cover $\leq 40 \%$ and smoothed with a $9 \times 9$ box-filter to remove noise. White-colored regions correspond to areas with no usable SCIAMACHY data.

seasonal trend peaking in the dry-season in response to increased isoprene emissions and $\mathrm{HCHO}$ released from biomass burning [Barkley et al., 2008]. The subsequent columns of Figures 3 and 4 which show the relative differences in the VCDs (or $\triangle \mathrm{VCD}$ ) arising from the sensitivity simulations outlined in Table 1, more importantly illustrate that the influence of the a priori isoprene emissions on the AMF computation, through their control on the $\mathrm{HCHO}$ profiles in the input climatology, can result in non-negligible spatial and temporal changes in the HCHO VCD distributions (see also Table S1).

[10] For example, when the isoprene emissions of the SCIA* and OMI* simulations are scaled downward to match the MEGAN estimates of Müller et al. [2008] (scenario: MEGAN'), the HCHO columns of the climatology are mostly lowered thereby increasing the AMFs, particularly over 

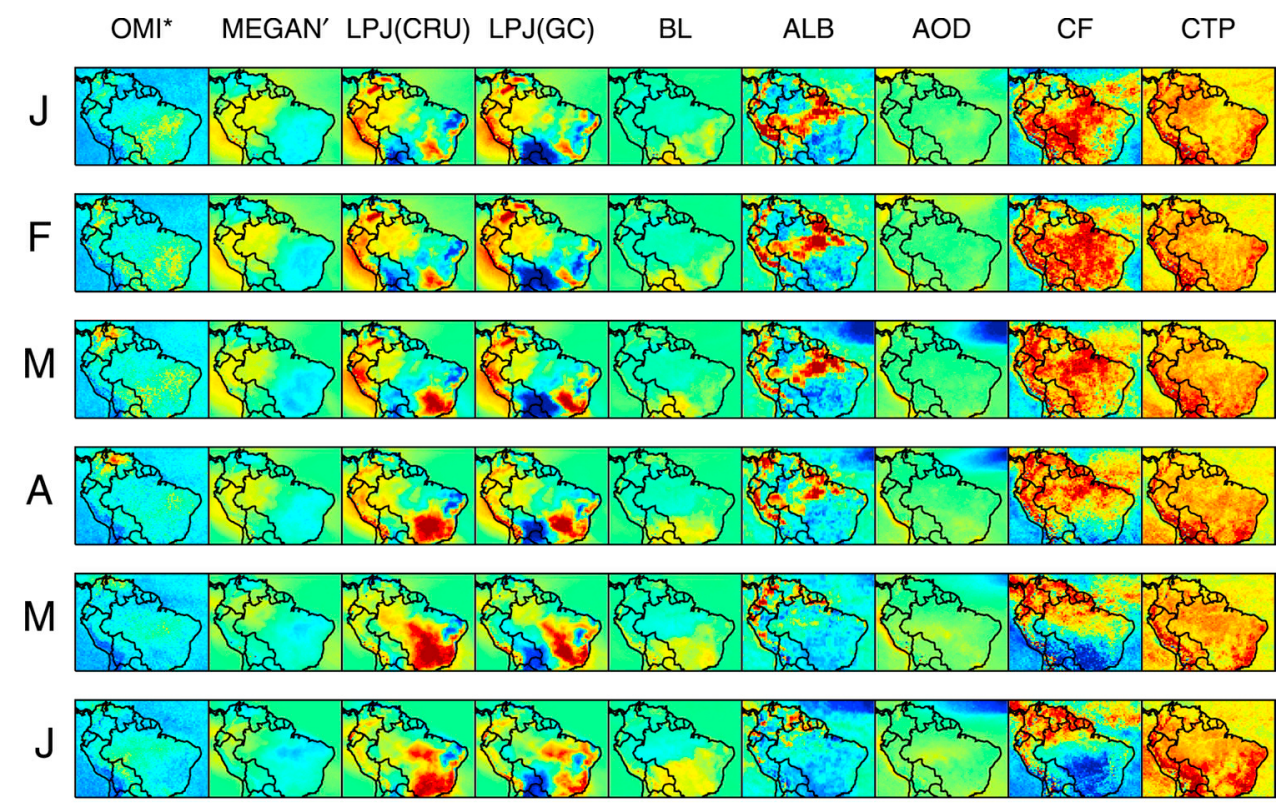

$\mathrm{J}$

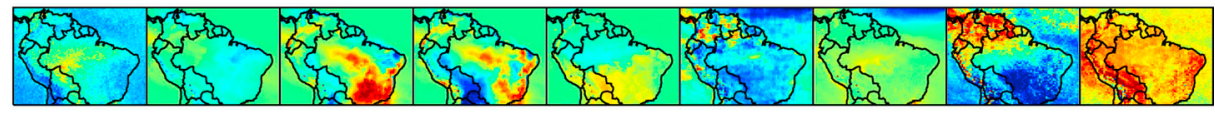

A
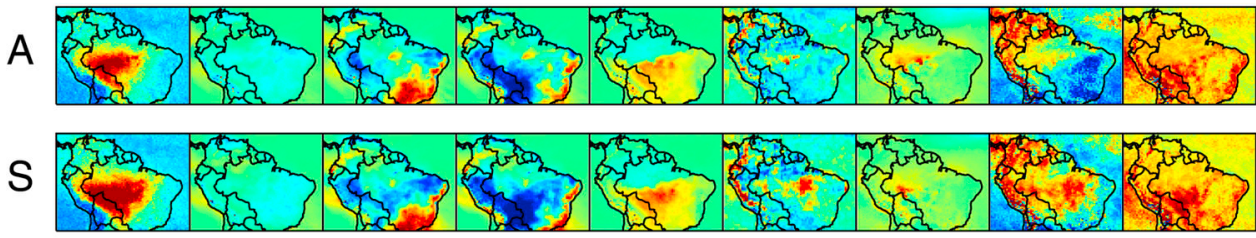

$\mathrm{O}$

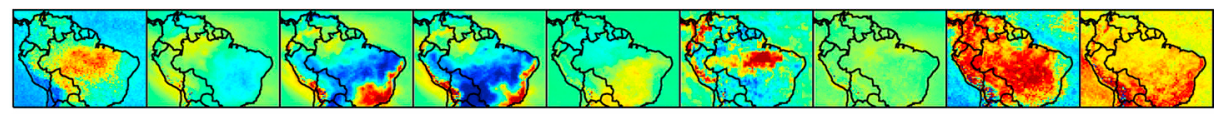

$\mathrm{N}$

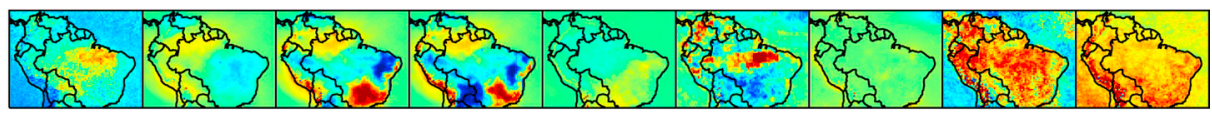

D
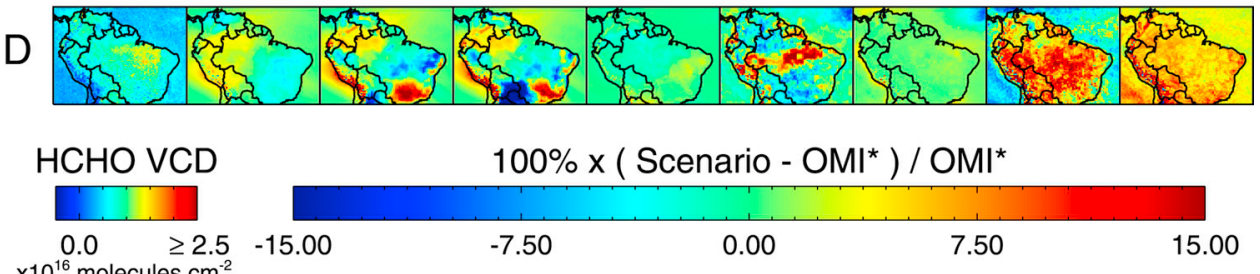

$100 \% \times\left(\right.$ Scenario $\left.-\mathrm{OMI}^{*}\right) / \mathrm{OMI}^{*}$

$\begin{array}{cr}0.0 & \geq 2.5 \\ \times 10^{16} \text { molecules } \mathrm{cm}^{-2}\end{array}$

$-7.50$

0.00

7.50

15.00

Figure 4. Monthly mean HCHO vertical columns for 2006 corresponding to 12:00-15:00 local time, as observed by OMI (first column) using AMFs based on the MEGAN bottom-up emission inventory. The remaining columns show the relative changes in the OMI HCHO VCDs arising from the sensitivity simulations outlined in Table 1. The OMI data have been averaged onto the nested $0.667^{\circ} \times 0.5^{\circ}$ grid using observations with cloud cover $\leq 40 \%$.

eastern areas. This results in correspondingly lower $\mathrm{HCHO}$ VCDs across these regions by on average only $2-3 \%$. However, the differences for individual grid cells can be larger, with $\triangle \mathrm{VCD}$ ranging from approximately $\pm 10 \%$ for both instruments.

[11] More dramatic changes in the HCHO VCDs are produced from the use of the alternative LPJ-GUESS emissions, which have very different spatial distributions to MEGAN (Figure S1). For instance, when GEOS-Chem's
GEOS-5 meteorological fields are used to drive the LPJGUESS model (scenario: LPJ(GC)), the reduced emissions yield a significantly lower HCHO climatology in most areas, except in the east and southeast during March-June. As a consequence, in those regions and months the AMFs are smaller by on average $2-10 \%$, and the VCDs larger by about $2-8 \%$, than in the SCIA* and $\mathrm{OMI}^{*}$ baseline simulations. Elsewhere, we typically find higher AMFs especially in western and southwestern areas during the dry season, 

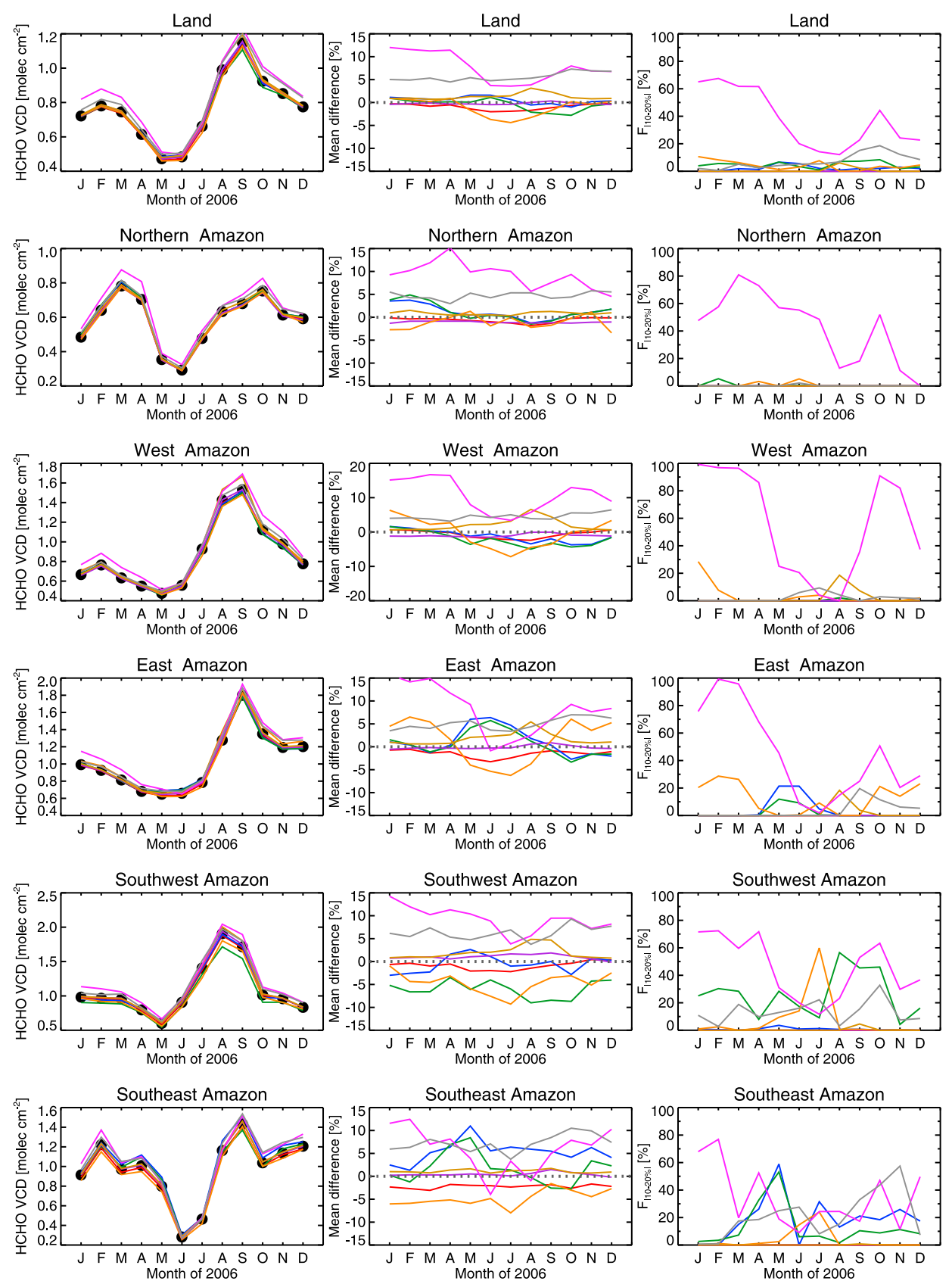

SCIA
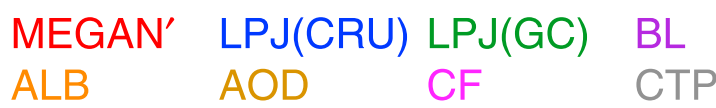

Figure 5. (left) Time series of the mean SCIAMACHY HCHO vertical columns (molecules $\mathrm{cm}^{-2}$ ) for different Amazon regions (defined in Figure 1). The black dots correspond to the SCIA* scenario whose AMFs were computed using a HCHO climatology based on the MEGAN bottom-up emission inventory (see section 2.1). The colored lines show the mean SCIAMACHY HCHO vertical columns determined using AMFs from the various sensitivity simulations as described in Table 1. (middle) Time series of the corresponding relative changes in the SCIAMACHY HCHO vertical columns $(\triangle \mathrm{VCD})$ arising from the AMF sensitivity simulations. (right) Time series of the percentage of grid cells that have a $|\triangle V C D|$ of between $10-20 \%\left(F_{|10-20 \%|}\right)$.

except along the northwest coast where the AMFs are lower in the early part of the year (Figures 1 and 2). Overall, over land $\triangle \mathrm{VCD}$ ranges from about $\pm 25 \%$ for SCIAMACHY, and $\pm 45 \%$ for OMI, though values exceeding $\pm 20 \%$ are infrequent on an annual basis (see Table S1). That said, for specific regions systematic differences in the $\mathrm{HCHO}$ VCDs can occur. For example, over the southwest the number of grid cells that have a $|\triangle V C D|$ of between $10-20 \%$ 

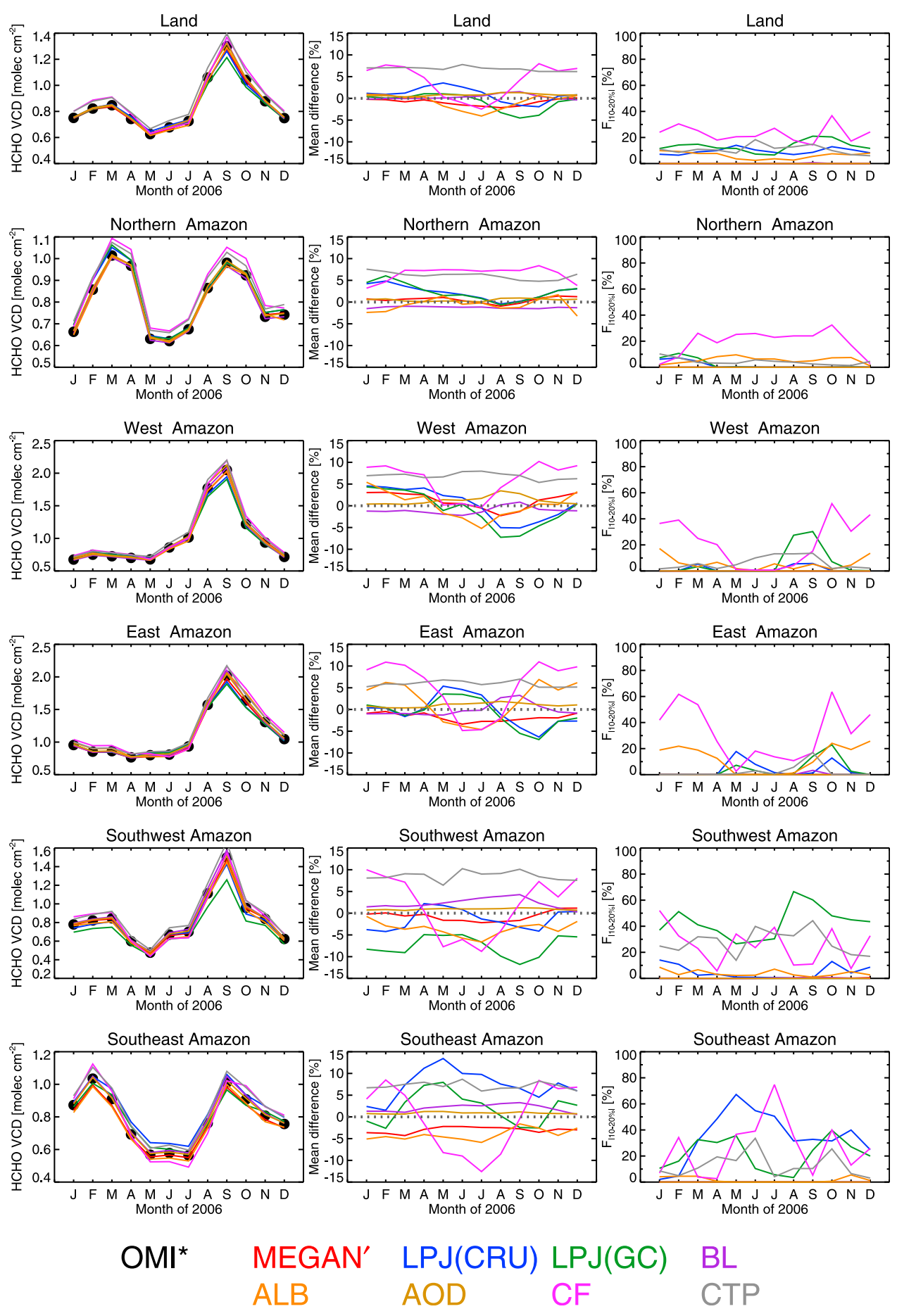

$B L$

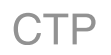

Figure 6. (left) Time series of the mean OMI HCHO vertical columns (molecules $\mathrm{cm}^{-2}$ ) for different Amazon regions (defined in Figure 1). The black dots correspond to the OMI* scenario whose AMFs were computed using a HCHO climatology based on the MEGAN bottom-up emission inventory (see section 2.1). The colored lines show the mean OMI HCHO vertical columns determined using AMFs from the various sensitivity simulations as described in Table 1. (middle) Time series of the corresponding relative changes in the OMI HCHO vertical columns $(\triangle \mathrm{VCD})$ arising from the AMF sensitivity simulations. (right) Time series of the percentage of grid cells that have a $|\triangle V C D|$ of between $10-20 \%\left(F_{|10-20 \%|}\right)$.

(hereafter denoted $F_{|10-20 \%|}$ ) are annually $28 \%$ and $43 \%$ for SCIAMACHY and OMI, respectively. The seasonal variation in $F_{|10-20 \%|}$ for SCIAMACHY and OMI over different Amazon regions can also be large, as shown in Figures 5 and 6. For instance, over the southwest during AugustOctober, OMI $F_{|10-20 \%|}$ is as high as $50-60 \%$, with $22 \%$ of grid cells having a $|\triangle V C D|$ of greater than $20 \%\left(F_{>20 \%}\right)$ in October alone. 
[12] Similarly, when the LPJ-GUESS model is forced with its default CRU meteorology (scenario: LPJ(CRU)), the HCHO climatology also has higher HCHO columns in southeastern regions, but this time throughout most of the year and particularly during May-July. For both instruments this results in lower AMFs and thus higher VCDs over these areas (monthly $\overline{\triangle \mathrm{VCD}}$ range from $2-15 \%$ ). The range of $\triangle \mathrm{VCD}$ is comparable to the $\mathrm{LPJ}(\mathrm{GC})$ scenario, typically $\pm 25 \%$ for SCIAMACHY and $\pm 40 \%$ for OMI, though the occurrence of such high values is rare. However, regional effects in $\triangle \mathrm{VCD}$ are again evident, but this time most notably over the southeast during April-July when $F_{110-20 \% 1}$ is often greater than $40 \%$ for OMI (Figure 6), or during May when $F_{|10-20 \%|}$ is nearly $60 \%$ for SCIAMACHY (Figure 5).

\subsection{Sensitivity to Other AMF Parameters}

[13] Despite the clear impact of the isoprene emissions on the AMFs, examination of the HCHO VCD time series, shown in Figures 5 and 6, reveals that while the VCD magnitudes may change, observed seasonal trends are largely unaffected by the choice of bottom-up inventory, i.e. most of the temporal variability comes from the spectral fitting of the SCDs. The question is therefore: are such relative changes significant when compared with the impact of other AMF inputs, or for that matter, other model processes that affect the HCHO profile such as boundary layer (BL) mixing? To determine the response of the VCDs to these effects, we separately recomputed AMFs using the SCIA* and $\mathrm{OMI}^{*}$ scenarios but with (a) no aerosol correction; (b) an alternative surface reflectance database derived from OMI [Kleipool et al., 2008]; (c) systematic errors of +0.1 in cloud fraction and $-60 \mathrm{hPa}$ in cloud-top pressure (typical uncertainties estimated by Acarreta et al. [2004]); and (d) with a GEOS-Chem HCHO climatology simulated with a more sophisticated non-local BL mixing scheme [Lin and McElroy, 2010], as opposed to a uniformly mixed $\mathrm{BL}$ in the default simulations.

[14] Owing to the relatively clean atmospheric conditions found over most undisturbed Amazonian regions, we find that the impact of switching off the aerosol correction (scenario: AOD) only has moderate effect on the SCIAMACHY and OMI AMFs and VCDs (assuming GEOS-Chem AODs are representative of the true aerosol conditions). We find differences in the HCHO VCDs of order $\pm 15 \%$ at most, which are therefore comparable with the effects of the a priori isoprene emissions. The most noteworthy changes in the AMFs actually occur over the Atlantic due to the presence of transported Saharan dust, and over central Amazon during July-September owing to the presence of black and organic carbonaceous aerosol from biomass burning. As a further test, we recalculated the AMFs but with the black and organic carbon AODs increased everywhere by an arbitrary $50 \%$ in order to simulate a high aerosol loading from fires, but this had only a minor effect on the SCIAMACHY and OMI HCHO columns with $\triangle$ VCD mostly $\pm 3 \%$. However, over biomass burning scenes the AMF can become highly sensitive to the relative vertical distribution of aerosols and HCHO [Fu et al., 2007]; aerosols underlying or coincident with the $\mathrm{HCHO}$ maximum typically increase measurement sensitivity [Gonzi et al., 2011]. To examine aerosol effects further, five additional simulations were conducted for the default, LPJ(CRU) and LPJ(GC) scenarios, in which the black and organic AOD profiles were adjusted depending if their emissions both exceeded $10^{9}$ molecules $\mathrm{cm}^{-2} \mathrm{~s}^{-1}$ and their individual maximum AOD occurred within the BL (see Figure S6 and auxiliary material for full details). Our results indicate that the HCHO VCD is not greatly affected if the aerosols are redistributed throughout and/or immediately above the $\mathrm{BL}(|\triangle V C D|<5 \%)$. Only when the AOD is distributed uniformly to higher altitudes $(\sim 5 \mathrm{~km})$ do substantial changes in the HCHO column occur. Aerosols at high altitudes shield the underlying $\mathrm{HCHO}$, reducing the AMFs and increasing the $\mathrm{HCHO}$ VCDs by as much $10-50 \%$ over regions of active burning (Figures S7 and S8). The magnitude of $\triangle \mathrm{VCD}$ is similar for both instruments but is more widespread for OMI since the modeled maximum AOD is more likely to reside in the deeper BL at its overpass. The impact of each aerosol simulation is generally consistent across the different isoprene emissions scenarios i.e. the $\mathrm{HCHO}$ profile over fire affected regions is more influenced by HCHO from burning vegetation than from oxidized biogenic emissions. The HCHO VCD is therefore potentially very sensitive to aerosols over areas of biomass burning, however, scenes affected by fires are often discarded when inferring top-down isoprene emissions [e.g., Barkley et al., 2008].

[15] Use of the new surface reflectances derived by Kleipool et al. [2008] also has a substantial impact on the AMFs and VCDs (scenario: ALB). The UV albedo over the rain forest is usually quite low $(<0.1)$ at the relevant wavelengths computed for the SCIAMACHY $(340 \mathrm{~nm})$ and OMI $(328 \mathrm{~nm}$ ) fitting windows and comparison of the two albedo data sets reveals significant differences (see Figure S9). The resulting changes in the $\mathrm{HCHO} A M F s$ and VCDs arise from the different resolutions and observing times of the albedo data (TOMS: $1.25^{\circ} \times 1.0^{\circ}$ and 12:00 LT, OMI: $0.5^{\circ} \times 0.5^{\circ}$ and 13:30 LT), the use of surface reflectances at wavelengths more appropriate to each instrument's spectral fitting window (328 nm for OMI and $342 \mathrm{~nm}$ for SCIAMACHY), and the fact that the Kleipool et al. [2008] data has been derived using the mode or $1 \%$ cumulative probability threshold of OMI measurements of Lambertian Equivalent Reflectivity (LER), instead of the minimum LER as in the TOMS data (which tends to underestimate the overall reflectivity of an observed scene). Typically, a high surface albedo increase measurement sensitivity to a lower tropospheric absorber such as $\mathrm{HCHO}$, since more solar radiation is reflected back to space [Palmer et al., 2001; De Smedt et al., 2008]. We find the AMFs are decreased where the newer albedo is lower than the Herman and Celarier [1997] values and higher where increased, thereby producing the converse effect in the HCHO vertical columns. Over land, $\triangle \mathrm{VCD}$ ranges from about $\pm 30 \%$ for SCIAMACHY, and $\pm 40 \%$ for OMI, but annually values of $F_{>20 \%}$ are low $(<1 \%)$. In spite of this, there are clear seasonal variations in $\triangle \mathrm{VCD}$ for some regions, e.g., in eastern and western areas where the mean difference is negative during May-July and positive outside this period (see Figures 5 and 6). Moreover, in eastern regions during October-March, $F_{110-20 \% 1}$ often exceeds $20 \%$ for both instruments, with $F_{>20 \%}$ nearly $10 \%$ for OMI during February-March.

[16] Previous studies have identified clouds as the main source of error on the AMF [e.g., Millet et al., 2006]. We 
Table 2. Estimated Bottom-Up and SCIAMACHY Top-Down Isoprene Emissions for $2006^{\mathrm{a}}$

\begin{tabular}{|c|c|c|c|c|c|}
\hline Scenario $^{b}$ & $\begin{array}{c}\text { Bottom-Up } \\
\text { a Priori } \\
\text { (Tg C) }\end{array}$ & $\begin{array}{l}\text { Top-Down }{ }^{\mathrm{C}} \\
\text { a Posterior } \\
\quad(\text { Tg C) }\end{array}$ & $\begin{array}{c}\text { Relative } \\
\text { Difference } \\
(\%)\end{array}$ & $\begin{array}{l}\text { Top-Down }{ }^{\mathrm{d}} \\
\text { a Posterior } \\
\text { (Tg C) }\end{array}$ & $\begin{array}{c}\text { Relative } \\
\text { Difference } \\
(\%)\end{array}$ \\
\hline \multicolumn{6}{|c|}{ Land } \\
\hline SCIA* & 365 & 151 & - & 151 & - \\
\hline $\mathrm{LPJ}(\mathrm{GC})$ & 171 & 215 & 42 & 146 & -3 \\
\hline LPJ(CRU) & 191 & 158 & 5 & 148 & -2 \\
\hline \multicolumn{6}{|c|}{ North Amazon } \\
\hline SCIA* & 40 & 16 & - & 16 & - \\
\hline $\mathrm{LPJ}(\mathrm{GC})$ & 23 & 22 & 38 & 18 & 13 \\
\hline LPJ(CRU) & 22 & 17 & 6 & 18 & 13 \\
\hline \multicolumn{6}{|c|}{ West Amazon } \\
\hline SCIA* & 83 & 21 & - & 21 & - \\
\hline LPJ(GC) & 26 & 31 & 48 & 21 & 0 \\
\hline LPJ(CRU) & 28 & 24 & 14 & 21 & 0 \\
\hline \multicolumn{6}{|c|}{ East Amazon } \\
\hline SCIA* & 71 & 40 & - & 40 & - \\
\hline LPJ(GC) & 38 & 58 & 45 & 39 & -3 \\
\hline LPJ(CRU) & 40 & 43 & 8 & 39 & -3 \\
\hline \multicolumn{6}{|c|}{ Southwest Amazon } \\
\hline SCIA* & 72 & 19 & - & 19 & - \\
\hline LPJ(GC) & 12 & 24 & 26 & 14 & -26 \\
\hline LPJ(CRU) & 26 & 22 & 16 & 18 & -5 \\
\hline \multicolumn{6}{|c|}{ Southeast Amazon } \\
\hline SCIA* & 20 & 11 & - & 11 & - \\
\hline LPJ(GC) & 18 & 15 & 36 & 11 & 0 \\
\hline LPJ(CRU) & 20 & 15 & 36 & 12 & 9 \\
\hline
\end{tabular}

${ }^{\mathrm{a}}$ Both the bottom-up and top-down isoprene emissions correspond to 09:00-11:00 local time coinciding with the overpass of SCIAMACHY (10:00). Relative differences calculated as $100 \% \times($ scenario - SCIA*)/ SCIA*.

${ }^{\mathrm{b}}$ Regions are shown in Figure 1 and scenarios described in Table 1.

${ }^{\mathrm{c}}$ Estimated using regression parameters from each individual scenario, as described in section 4 .

${ }^{\mathrm{d}}$ Estimated using regression parameters from the default SCIA* scenario, as described in section 4 .

also find the largest changes in the AMFs and VCDs by assigning a +0.1 error in cloud fraction (achieved by increasing $f$ for each observation by 0.1 in equation (1) after being cloud filtered using its original value; scenario: $C F$ ). For SCIAMACHY, the subsequent AMFs are in general reduced (by about 4\%) as less weight is placed on the clearsky sub-scene AMF, thereby increasing the VCDs over land by on average $8 \%$ (range: 55 to $-41 \%$ ). The largest decrease in the AMFs occur during January-April (i.e. the wet season) resulting in a widespread changes in $\triangle \mathrm{VCD}$, with $F_{|10-20 \%|}$ often greater than $50 \%$ during these months. For OMI, the AMFs are also reduced in most continental areas increasing the $\mathrm{HCHO}$ VCDs by $4 \%$ (range: 70 to $-73 \%$ ), with $F_{110-20 \% \mid}$ varying between $15-30 \%$ over land (Figure 6 ). The only exception being in southern regions during AprilAugust when the AMFs are increased by on average 5-21\%, and the VCDs decreased by $4-13 \%$. Increasing the cloud fraction increases the AMF in some regions because of the cloud albedo effect, whereby low-level clouds that reside underneath or with the peak of the $\mathrm{HCHO}$ profile increase measurement sensitivity [De Smedt, 2011]. A further simulation where we decreased $f$ by 0.1 produced similar changes but of the opposite sign. Use of stricter cloud-filter $(20 \%)$ with a +0.1 increase in $f$, typically produces larger values of $\triangle$ VCD (not shown), with $F_{>20 \%}$ varying between $10-30 \%$ for both instruments. By comparison, a $60 \mathrm{hPa}$ systematic error in the cloud-top pressure (scenario: CTP) has a lesser but still significant impact on the AMFs and VCDs than a 0.1 error in cloud fraction. A higher altitude (i.e. lower) cloud-top pressure yields a lower AMF [De Smedt et al., 2008], thus on average for both instruments we determine consistent decreases and increases in the AMFs and VCDs over land of about $-6 \%$ and $6 \%$, respectively, though for some months and locations the differences can be up to $20 \%$.

[17] The choice of BL mixing scheme within GEOSChem can strongly influence near surface mixing ratios of isoprene and its oxidation products, including the vertical distribution of HCHO [Barkley et al., 2011]. The non-local mixing scheme can sometimes produces very different HCHO profile shapes compared with default full-mixing scheme (Figure S2), with the effect often more pronounced at the time of OMI's overpass. However, we find the effect of the non-local mixing scheme (scenario: BL) on the input HCHO climatology, results in only a moderate impact on the SCIAMACHY with $\triangle \mathrm{AMFs}$ of about $\pm 3 \%$ and $\triangle \mathrm{VCDs}$ of $\pm 10 \%$. For OMI, the differences are slightly larger with $\triangle \mathrm{AMFs}$ ranging from 4 to $-10 \%$ and $\triangle \mathrm{VCDs}$ from 18 to $-23 \%$, though mostly $\triangle \mathrm{VCDs}$ varies between $\pm 10 \%$. The effects of BL mixing are therefore comparable with other AMF uncertainties, with the greater impact on OMI most likely reflecting a deeper and more often mixed BL at its overpass time.

\section{Implications for Top-Down Isoprene Emissions Estimates}

[18] To highlight what these VCD differences potentially imply for subsequent top-down isoprene emissions, as a sensitivity test, we estimate isoprene emissions from SCIAMACHY and OMI HCHO VCDs, computed using AMFs from the SCIA*, OMI*, and appropriate $\mathrm{LPJ}(\mathrm{GC})$ and $\mathrm{LPJ}(\mathrm{CRU})$ simulations. To infer the top-down estimates we adopt the approach of Palmer et al. [2003], whereby we linearly regress the model isoprene emissions and $\mathrm{HCHO}$ vertical columns to determine the gradient and intercept, which we transpose and apply to the corresponding OMI HCHO VCDs from each scenario [see also Barkley et al., 2008]. As rigorous estimates are not required in this instance, we neglect the effects of spatial smearing associated with delayed $\mathrm{HCHO}$ production, as well as other model uncertainties, but remove scenes influenced by fires using ATSR fire count data [Barkley et al., 2008]. Note, in a follow study we will present an ensemble of robust top-down estimates in which we pay strict attention to these error sources.

[19] Since differences in the top-down estimates occur due to changes in the retrieved $\mathrm{HCHO}$ VCDs, and the linear regression relationship obtained from each simulation we use two methods to infer top-down isoprene emissions. First, we run GEOS-Chem with each scenario's specified emissions, calculate the linear transfer function from the subsequent model $\mathrm{HCHO}$ columns and isoprene emissions, and then apply it to the observed HCHO VCDs, computed using AMFs corresponding to that simulation. Second, we use the gradient and intercept from our default SCIA* and OMI* simulations, and apply them to the observed HCHO VCDs determined using AMFs from the LPJ $(\mathrm{GC})$ and LPJ(CRU) 
Table 3. Estimated Bottom-Up and OMI Top-Down Isoprene Emissions for $2006^{\mathrm{a}}$

\begin{tabular}{|c|c|c|c|c|c|}
\hline Scenario $^{\mathrm{b}}$ & $\begin{array}{l}\text { Bottom-Up } \\
\text { a Priori } \\
\text { (Tg C) }\end{array}$ & $\begin{array}{c}\text { Top-Down } \\
\text { a Posterior } \\
(\mathrm{Tg} \mathrm{C})\end{array}$ & $\begin{array}{l}\text { Relative } \\
\text { Difference } \\
(\%)\end{array}$ & $\begin{array}{l}\text { Top-Down } \\
\text { a Posterior } \\
(\mathrm{Tg} \mathrm{C})\end{array}$ & $\begin{array}{c}\text { Relative } \\
\text { Difference } \\
(\%)\end{array}$ \\
\hline \multicolumn{6}{|c|}{ Land } \\
\hline OMI* & 435 & 197 & - & 197 & - \\
\hline LPJ(GC) & 200 & 234 & 19 & 192 & -3 \\
\hline LPJ(CRU) & 240 & 184 & -7 & 197 & 0 \\
\hline \multicolumn{6}{|c|}{ North Amazon } \\
\hline OMI* & 43 & 20 & - & 21 & - \\
\hline $\mathrm{LPJ}(\mathrm{GC})$ & 24 & 24 & 20 & 20 & 5 \\
\hline LPJ(CRU) & 23 & 20 & 0 & 20 & 5 \\
\hline \multicolumn{6}{|c|}{ West Amazon } \\
\hline OMI* & 95 & 28 & - & 28 & - \\
\hline $\operatorname{LPJ}(\mathrm{GC})$ & 29 & 35 & 25 & 27 & -4 \\
\hline LPJ(CRU) & 32 & 29 & 4 & 28 & 0 \\
\hline \multicolumn{6}{|c|}{ East Amazon } \\
\hline OMI* & 77 & 51 & - & 51 & - \\
\hline LPJ(GC) & 41 & 60 & 18 & 49 & -4 \\
\hline LPJ(CRU) & 43 & 46 & -10 & 49 & -4 \\
\hline \multicolumn{6}{|c|}{ Southwest Amazon } \\
\hline OMI* & 98 & 29 & - & 29 & - \\
\hline LPJ(GC) & 16 & 29 & 17 & 21 & -28 \\
\hline LPJ(CRU) & 37 & 29 & 0 & 27 & -7 \\
\hline \multicolumn{6}{|c|}{ Southeast Amazon } \\
\hline OMI* & 31 & 19 & - & 19 & - \\
\hline LPJ(GC) & 32 & 27 & 42 & 20 & 5 \\
\hline LPJ(CRU) & 53 & 23 & 21 & 23 & 21 \\
\hline
\end{tabular}

${ }^{\mathrm{a}}$ Both the bottom-up and top-down isoprene emissions correspond to 12:00-15:00 local time coinciding with the overpass of OMI (13:30). Relative differences calculated as $100 \% \times($ scenario - OMI*)/OMI*.

${ }^{\mathrm{b}}$ Regions are shown in Figure 1 and scenarios described in Table 1.

${ }^{c}$ Estimated using regression parameters from each individual scenario, as described in section 4 .

${ }^{\mathrm{d} E s t i m a t e d ~ u s i n g ~ r e g r e s s i o n ~ p a r a m e t e r s ~ f r o m ~ t h e ~ d e f a u l t ~ O M I * ~ s c e n a r i o, ~}$ as described in section 4 .

scenarios. This latter approach ensures any differences in the inferred top-down emissions are due to changes in the observed HCHO VCDs alone. We show in Tables 2 and 3 the results of both methods, when applied to the observed SCIAMACHY and OMI HCHO VCDs.

[20] Focussing on OMI, we find using individual regression parameters results in large differences between the topdown estimates, as the annual isoprene emissions over land inferred from the OMI*, LPJ(GC) and LPJ(CRU) scenarios are 197, 234, and $184 \mathrm{Tg} \mathrm{C}$ respectively, at the time of the instruments's overpass (Table 3). However, for individual regions the differences in the top-down emissions can be much larger, e.g., in the southeast where the $\mathrm{LPJ}(\mathrm{GC})$ and LPJ(CRU) estimates are $21 \%$ and $42 \%$ higher than those determined from the $\mathrm{OMI}^{*}$ scenario. When using the gradient and intercept from the default $\mathrm{OMI}^{*}$ simulation alone, which eliminates compensating effects between the $\triangle \mathrm{VCDs}$ and the regression parameters, we find for most regions the differences between the top-down estimates are smaller, as its only the only changes in the HCHO VCDs that matter. The only exception being the southwest region where the LPJ based estimates are $28 \%$ and $7 \%$ lower than the OMI* derived emission. These traits are also consistent in the topdown estimates determined from SCIAMACHY (Table 2).
For example, over land the annual isoprene emissions inferred in the SCIA*, LPJ(GC) and LPJ(CRU) scenarios are 151,215 , and $158 \mathrm{Tg} \mathrm{C}$ respectively when using the individual regression parameters, and 151, 146, and $148 \mathrm{Tg} \mathrm{C}$ using the SCIA* gradient and intercept (which typically brings the top-down estimates in closer agreement for most regions).

[21] Therefore, as this simple exercise illustrates, the use of two bottom-up inventories to compute SCIAMACHY and OMI AMFs and VCDs, can potentially lead to differences of up to $\pm 30-50 \%$ in the top-down emission estimates, depending on the region studied and inference technique used. In spite of this, the top-down estimates generally agree more closely than the a priori inventories demonstrating the likely value of $\mathrm{HCHO}$ columns for constraining surface isoprene emissions.

\section{Conclusions}

[22] The AMF calculation is a critical step in the $\mathrm{HCHO}$ retrieval. Computing HCHO AMFs using a specified CTM and bottom-up isoprene emission inventory, ensures some degree of self-consistency for subsequent model-satellite comparisons and inference of top-down isoprene emission. However, we have shown that at least for tropical South America, the use of different isoprene emission inventories within the same CTM can cause non-negligible changes in the resulting HCHO VCD monthly distributions, and in some cases very large differences for individual locations and months. The size of these relative changes are at least comparable to those originating from other sources of uncertainty in the AMF calculation, such as aerosols or the surface albedo, but are potentially less than the relative changes associated with errors in cloud fractional coverage. While we find that large-scale seasonal trends are generally unaffected by the use of the two differing isoprene inventories, we do observe notable changes in the HCHO column magnitudes that will clearly impact on any inferred topdown emissions. Consistent with our previous work [Barkley et al., 2011], we advocate that satellite-based estimates of isoprene emissions over this region will be better characterized using two alternative bottom-up emission inventories to compute the HCHO AMFs and VCDs, than estimates based on a single emission scheme alone. Whether this is case for other areas, where isoprene emissions rates are significantly less than those from tropical vegetation, is unclear. However, we strongly advise that any future topdown estimates of isoprene emissions should properly assess this source of uncertainty. Furthermore, since satellite derived emissions are the only way to constrain isoprene fluxes from the entire Amazon, it is requirement that retrieved HCHO VCDs are well validated and their errors/ biases appropriately characterized. In situ measurements of the HCHO profile and aerosol distribution within the lower troposphere coincident with each satellite's overpass would help resolve the accuracy of calculated AMFs and VCDs, but over the Amazon such measurements are rare. Given the large uncertainties associated with this regions's isoprene emissions, oxidation chemistry and aerosol loading, we therefore emphasize the need for a dedicated aircraft campaign over the Amazon that could provide such observations, complemented by ground-based observations (e.g., 
lidar or DOAS), to give a critical assessment of the satellite $\mathrm{HCHO}$ columns where arguably the data is most useful.

[23] Acknowledgments. This work was supported by the Natural Environment Research Council (grant NE/GE013810/2). A.A. and D.H. acknowledge support from the Swedish Research Council Formas.

\section{References}

Acarreta, J. R., J. F. De Haan, and P. Stammes (2004), Cloud pressure retrieval using the $\mathrm{O}_{2}-\mathrm{O}_{2}$ absorption band at $477 \mathrm{~nm}, J$. Geophys. Res. 109, D05204, doi:10.1029/2003JD003915.

Arneth, A., et al. (2007), Process-based estimates of terrestrial ecosystem isoprene emissions: incorporating the effects of a direct $\mathrm{CO}_{2}$-isoprene interaction, Atmos. Chem. Phys., 7(1), 31-53, doi:10.5194/acp-7-31-2007.

Arneth, A., R. K. Monson, G. Schurgers, U. Niinemets, and P. I. Palmer (2008), Why are estimates of global terrestrial isoprene emissions so similar (and why is this not so for monoterpenes)?, Atmos. Chem. Phys., 8(16), 4605-4620, doi:10.5194/acp-8-4605-2008.

Barkley, M. P., P. I. Palmer, U. Kuhn, J. Kesselmeier, K. Chance, T. P. Kurosu, R. V. Martin, D. Helmig, and A. Guenther (2008), Net ecosystem fluxes of isoprene over tropical South America inferred from GOME observations of HCHO columns, J. Geophys. Res., 113, D20304, doi:10.1029/ 2008JD009863.

Barkley, M. P., P. I. Palmer, I. D. Smedt, T. Karl, A. Guenther, and M. V. Roozendael (2009), Regulated large-scale annual shutdown of Amazonian isoprene emissions?, Geophys. Res. Lett., 36, L04803, doi:10.1029/ 2008 GL036843.

Barkley, M. P., et al. (2011), Can a 'state of the art' chemistry transport model simulate Amazonian tropospheric chemistry?, J. Geophys. Res., 116, D16302, doi:10.1029/2011JD015893.

Bovensmann, H., J. P. Burrows, M. Buchwitz, J. Frerick, S. Nöel, V. V. Rozanov, K. V. Chance, and A. Goede (1999), SCIAMACHY - mission objectives and measurement modes, J. Atmos. Sci., 56, 127-150.

Chance, K. (2002), OMI algorithm theoretical basis document, volume IV: OMI trace gas algorithms, ATBD-OMI-04, NASA, Washington, D. C.

De Smedt, I. (2011), Long-term global observations of tropospheric formaldehyde retrieved from spaceborne Nadir UV sensors, PhD thesis, Fac. of Appl. Sci., Univ. of Brussels, Belgium.

De Smedt, I., J.-F. Müller, T. Stavrakou, R. van der A, H. Eskes, and M. V. Roozendael (2008), Twelve years of global observation of formaldehyde in the troposphere using GOME and SCIAMACHY sensors, Atmos. Chem. Phys., 8(16), 4947-4963, doi:10.5194/acp-8-4947-2008.

Fu, T.-M., D. J. Jacob, P. I. Palmer, K. Chance, Y. X. Wang, B. Barletta D. R. Blake, J. C. Stanton, and M. J. Pilling (2007), Space-based formaldehyde measurements as constraints on volatile organic compound emissions in east and south Asia and implications for ozone, J. Geophys. Res., 112, D06312, doi:10.1029/2006JD007853.

Gonzi, S., P. I. Palmer, M. P. Barkley, I. D. Smedt, and M. V. Roozendael (2011), Biomass burning emission estimates inferred from satellite column measurements of HCHO: Sensitivity to co-emitted aerosol and injection height, Geophys. Res. Lett., 38, L14807, doi:10.1029/2011GL047890.

Guenther, A., B. Baugh, G. Brasseur, J. Greenberg, P. Harley, L. Klinger, D. Serça, and L. Vierling (1999), Isoprene emission estimates and uncertainties for the Central African EXPRESSO study domain, J. Geophys. Res., 104(D23), 30,625-30,639, doi:10.1029/1999JD900391.

Guenther, A., T. Karl, P. Harley, C. Wiedinmyer, P. I. Palmer, and C. Geron (2006), Estimates of global terrestrial isoprene emissions using MEGAN (Model of Emissions of Gases and Aerosols from Nature), Atmos. Chem. Phys., 6(11), 3181-3210, doi:10.5194/acp-6-3181-2006.

Herman, J. R., and E. A. Celarier (1997), Earth surface reflectivity climatology at 340-380 nm from TOMS data, J. Geophys. Res., 102(D23), 28,003-28,011, doi:10.1029/97JD02074.
Kleipool, Q. L., M. R. Dobber, J. F. de Haan, and P. F. Levelt (2008), Earth surface reflectance climatology from 3 years of OMI data, J. Geophys. Res., 113, D18308, doi:10.1029/2008JD010290.

Koelemeijer, R. B. A., P. Stammes, J. W. Hovenier, and J. F. de Haan (2002), Global distributions of effective cloud fraction and cloud top pressure derived from oxygen A band spectra measured by the Global Ozone Monitoring Experiment: Comparison to ISCCP data, J. Geophys. Res., 107(D12), 4151, doi:10.1029/2001JD000840.

Kurosu, T. P., K. Chance, and C. Sioris (2004), Preliminary results for $\mathrm{HCHO}$ and $\mathrm{BrO}$ from the EOS-Aura Ozone Monitoring Instrument, in Passive Optical Remote Sensing of the Atmosphere and Clouds IV, edited by S. C. Tsay, T. Yokota, and M.-H. Ahn, Proc. SPIE Int. Soc. Opt. Eng., 5652, 116-123, doi:10.1117/12.578606.

Levelt, P. F., et al. (2006), The Ozone Monitoring Instrument, IEEE Trans. Geosci. Remote Sens., 44(5), 1093-1101, doi:10.1109/TGRS.2006.872333.

Lin, J.-T., and M. B. McElroy (2010), Impacts of boundary layer mixing on pollutant vertical profiles in the lower troposphere: Implications to satellite remote sensing, Atmos. Environ., 44, 1726-1739.

Martin, R. V., et al. (2002), An improved retrieval of tropospheric nitrogen dioxide from GOME, J. Geophys. Res., 107(D20), 4437, doi:10.1029/ 2001JD001027.

Millet, D. B., et al. (2006), Formaldehyde distribution over North America: Implications for satellite retrievals of formaldehyde columns and isoprene emission, J. Geophys. Res., 111, D24S02, doi:10.1029/2005JD006853.

Müller, J.-F., et al. (2008), Global isoprene emissions estimated using MEGAN, ECMWF analyses and a detailed canopy environment model, Atmos. Chem. Phys., 8(5), 1329-1341, doi:10.5194/acp-8-1329-2008.

Palmer, P. I., D. J. Jacob, K. Chance, R. V. Martin, R. J. D. Spurr, T. P. Kurosu, I. Bey, R. Yantosca, A. Fiore, and Q. Li (2001), Air mass factor formulation for spectroscopic measurements from satellites: Application to formaldehyde retrievals from the Global Ozone Monitoring Experiment, J. Geophys. Res., 106, 14,539-14,550, doi:10.1029/2000JD900772.

Palmer, P. I., D. J. Jacob, A. M. Fiore, R. V. Martin, K. Chance, and T. P. Kurosu (2003), Mapping isoprene emissions over North America using formaldehyde column observations from space, J. Geophys. Res., 108(D6), 4180, doi:10.1029/2002JD002153.

Palmer, P. I., et al. (2006), Quantifying the seasonal and interannual variability of North American isoprene emissions using satellite observations of formaldehyde column, J. Geophys. Res., 111, D12315, doi:10.1029/ 2005JD006689.

Paulot, F., J. D. Crounse, H. G. Kjaergaard, J. H. Kroll, J. H. Seinfeld, and P. O. Wennberg (2009a), Isoprene photooxidation: new insights into the production of acids and organic nitrates, Atmos. Chem. Phys., 9(4), 1479-1501, doi:10.5194/acp-9-1479-2009.

Paulot, F., J. D. Crounse, H. G. Kjaergaard, A. Kurten, J. M. St. Clair, J. H. Seinfeld, and P. O. Wennberg (2009b), Unexpected epoxide formation in the gas-phase photooxidation of isoprene, Science, 325(5941), 730-733, doi:10.1126/science. 1172910 .

Rienecker, M., et al. (2008), The GEOS-5 Data Assimilation SystemDocumentation of Versions 5.0.1, 5.1.0, and 5.2.0, NASA/TM-2008104606, Global Model. and Assimilation Off., NASA Goddard Space Flight Cent., Greenbelt, Md.

Spurr, R. J. D., T. P. Kurosu, and K. Chance (2001), A linearized discrete ordinate radiative transfer model for atmospheric remote sensing retrieval, J. Quant. Spectrosc. Radiat. Transfer, 68(6), 689-735.

Stavrakou, T., J.-F. Müller, I. De Smedt, M. Van Roozendael, G. R. van der Werf, L. Giglio, and A. Guenther (2009a), Evaluating the performance of pyrogenic and biogenic emission inventories against one decade of spacebased formaldehyde columns, Atmos. Chem. Phys., 9(3), 1037-1060, doi:10.5194/acp-9-1037-2009.

Stavrakou, T., J.-F. Müller, I. De Smedt, M. Van Roozendael, G. R. van der Werf, L. Giglio, and A. Guenther (2009b), Global emissions of nonmethane hydrocarbons deduced from SCIAMACHY formaldehyde columns through 2003-2006, Atmos. Chem. Phys., 9(11), 3663-3679, doi:10.5194/acp-9-3663-2009. 